\title{
New Frontiers for Stroke Prevention in Atrial Fibrillation
}

\author{
Vinayak Prasad Rachel M. Kaplan Rod S. Passman \\ Northwestern University Feinberg School of Medicine, Chicago, III., USA
}

\section{Key Words}

Stroke prevention · Atrial fibrillation • Anticoagulation

\begin{abstract}
Atrial fibrillation (AF) is the most common sustained arrhythmia, affects over 2.5 million people in the USA and is responsible for one fifth of the 700,000 ischemic strokes per year. For the last 50 years, long-term anticoagulation with warfarin has been the most effective therapy for preventing stroke in patients with AF and other risk factors. However, many AF patients are poor candidates for this treatment, and management of the drug can be challenging. Such challenges include the need for frequent monitoring, interactions with food and other medications, variability in metabolism and a delayed onset of action. Antiplatelet therapy has also been evaluated, and though it is not as effective at preventing ischemic strokes, it may provide some benefit for patients who cannot tolerate warfarin. Recent clinical trials have tested pharmacologic alternatives to warfarin, and new treatment options have emerged. Of these alternatives, the direct oral thrombin inhibitor dabigatran and the oral factor Xa inhibitor rivaroxaban, which have minimal interactions and require no INR monitoring, have already been approved by the FDA. The field may soon be further expanded as the oral factor Xa inhibitor apixaban has shown promise in its recent phase 3 trial and is under consideration for FDA approval. Nonpharmacologic approaches to stroke prevention in AF are under development as well. These approaches focus on occlusion or ligation of the left atrial appendage, which is frequently the location of thrombus formation. While such
\end{abstract}

procedures have been done often during other cardiac surgeries, newer methods have focused on percutaneous techniques, including ones that may not require anticoagulation afterwards. In addition, new diagnostic modalities may detect paroxysmal AF with more sensitivity, potentially expanding the population to be treated and the potential impact of stroke preventive strategies on the population. This review provides a practical guide to current treatment and diagnostic options and focuses on emerging therapies.

Copyright $\odot 2012$ S. Karger AG, Basel

\section{Introduction}

Affecting nearly 2.5 million people, atrial fibrillation (AF) is the most common sustained arrhythmia encountered in clinical practice [1]. AF is independently associated with a 5-fold increased risk of stroke and, as such, is estimated to account for more than 140,000 instances of ischemic stroke per year in the USA [2-4]. Strokes that occur due to AF are particularly severe and disabling; therefore, stroke prevention is of great importance in this population $[5,6]$.

Anticoagulation with the vitamin $\mathrm{K}$ antagonist warfarin has been the optimal therapy for the prevention of stroke in moderate- to high-risk patients with AF. Pooled data from pivotal trials found that dose-adjusted warfarin reduced the risk of stroke by $68 \%$, from an annual risk of $4.5 \%$ (placebo) to $1.4 \%$ (warfarin) [7]. In a similar patient population, aspirin showed a more modest effect, reducing the risk of stroke by a relative factor of $21 \%$ [8].

\section{KARGER \\ Fax +4161306 1234 \\ E-Mail karger@karger.ch}

www.karger.com

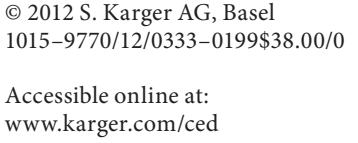

Rod S. Passman, MD, MSCE

Northwestern Memorial Hospital

201 East Huron, Feinberg Suite 8-503

Chicago, IL 60611 (USA)

Tel. +1 312926 5342, E-Mail r-passman@northwestern.edu 
Other studies have extended these findings to the very elderly, a patient population frequently undertreated with warfarin [9].

Although warfarin is effective in preventing ischemic stroke in patients with moderate- to high-risk AF, its use can be challenging. Warfarin therapy is complicated by interactions with food and other drugs, variability in metabolism, a delayed onset of action and requirement for regular monitoring $[10,11]$. The therapeutic index is narrow, with an increased risk of stroke when the INR falls below 2 and an increased risk of hemorrhage when the INR rises above 3 [12]. Patients who were monitored by specialized anticoagulation clinics were out of the therapeutic range about $37 \%$ of the time, and warfarin patients monitored in community-based settings were out of the therapeutic range $49 \%$ of the time $[13,14]$. Warfarin-associated hemorrhage results in a mortality of $42 \%$ with another $34 \%$ of patients suffering from major disability [15]. While this risk is greater at INR values over 3.5, there is still a risk of intracerebral hemorrhage at therapeutic INR levels and even at subtherapeutic levels [16]. For these reasons and others, only half of the patients with AF who are appropriate candidates are prescribed warfarin in retrospective analyses of outpatient records $[17,18]$.

Alternatives to warfarin have been actively sought, and several will be reviewed here. Recent trials of alternate drug regimens, devices and interventions shed light on the promise and difficulties of these efforts. Other avenues of research are being pursued with respect to stroke and AF. A basic review of the pathophysiology of AF may serve as a foundation for these attempts.

\section{Basic Mechanisms}

AF causes stroke by formation of thrombus in the left atrium, usually the left atrial appendage (LAA), and subsequent embolism to the brain [19]. A growing body of evidence supports the link between AF and endothelial dysfunction, which may in part explain the relationship between AF, cardiovascular risk factors and stroke [20].

Endothelial dysfunction is a maladaptive state of endothelial cells, characterized by a constellation of impaired physiologic responses including: poor regulation of arterial tone, increased proinflammatory and prothrombotic mediators, overexpression of adhesion molecules and impaired endothelium-dependent vasodilation [20]. Experimental AF has been associated with these features and additionally enhanced platelet activation $[20,21]$. Takahashi et al. [22] measured forearm blood flow before and after acetylcholine (a vasodilator) in patients with AF and controls. They then repeated the measurements after cardioversion to sinus rhythm in the AF group. Compared with controls, they found smaller increases in forearm blood flow during the AF state. They subsequently noted improved responsiveness to acetylcholine after cardioversion to sinus rhythm. This observation suggests that the fibrillatory state is associated with systemic changes in vasoreactiveness that may contribute to thrombus formation. Others have extended these findings, noting that when AF is accompanied by underlying comorbidities (such as diabetes and hypertension), the improvement in forearm blood flow after cardioversion is smaller than among those without comorbidities [23, 24].

Endothelial dysfunction may thus be particularly relevant in patients with other underlying disorders, such as hypertension and diabetes, and may offer some explanation as to why AF patients without other risk factors (i.e. those with 'lone AF') have a low risk of stroke. Because of this research, improved risk stratification schemes are already being pursued, which aim to more accurately delineate the risk of stroke. Markers of endothelial dysfunction such as von Willebrand's factor have been found to be elevated in AF patients as compared to patients with other forms of supraventricular tachyarrhythmias [25]. Levels of von Willebrand's factor have been used in risk stratification for AF patients and were shown to be an independent risk factor for adverse events in these patients [26].

\section{Risk Factors}

Major risk factors for stroke in the setting of AF include age greater than 75 years, congestive heart failure, hypertension, diabetes, smoking and other structural lesions of the heart [8]. Most prominently, patients with a prior stroke or transient ischemic attack (TIA) and AF face the highest risk, more than twice that of AF patients without such a history. These factors have been incorporated into risk stratification tools such as the commonly used $\mathrm{CHADS}_{2}$ score $(\mathrm{C}=$ congestive heart failure, $\mathrm{H}=$ history of hypertension, $\mathrm{A}=$ age $\geq 75$ years, $\mathrm{D}=$ diabetes, $S=$ prior stroke or TIA). Stroke or prior TIA is assigned 2 points, while the other risk factors count for 1 point each. This 0 - to 6-point scale can be used to quantify the patient's risk of stroke and thus guide decision making regarding the need for anticoagulation. As a $\mathrm{CHADS}_{2}$ score of 2 is generally accepted as the level at which anticoagulation should be administered, it should be noted 
that any patient with a history of stroke or TIA has automatically reached this threshold. More modest risk factors include female gender, and presence of coronary artery disease or peripheral vascular disease [27]. Age is a critical risk factor as the risk of stroke due to AF increases from an absolute risk of 2.2 for individuals aged 60-69 to 4.2 (ages 70-79) and 5.1 (ages 80-89) [28]. These additional factors are included in the scoring system $\mathrm{CHA}_{2} \mathrm{DS}_{2}$-VASc which also considers the presence of vascular disease $(\mathrm{V})$, age between 65 and 74 years and female gender $(\mathrm{Sc})$ [26]. This expanded scoring system is most useful at risk-stratifying those patients at the lower end of the $\mathrm{CHADS}_{2}$ spectrums [29]. Additional risk factors include echocardiographic findings of complex aortic plaque or functional left atrial abnormalities, such as presence of thrombus, diminished peak blood flow velocities and dense spontaneous echo contrast [30].

The relationship between the duration of AF episodes and the risk of stroke is also a subject of increasing interest. Though paroxysmal and persistent AF have similar stroke risks, there is no clear threshold for the AF duration necessary to form a thrombus in the left atrium [8]. A period of $48 \mathrm{~h}$ has generally been accepted as the period before which cardioversion can be performed without the need for prior anticoagulation or transesophageal echocardiography, but studies of patients being continually monitored via their implanted cardiac rhythm management devices - i.e. pacemakers and defibrillators - render this threshold questionable.

Capucci et al. [31] studied 725 pacemaker patients with a history of atrial tachyarrhythmias, two thirds of whom were receiving antithrombotic therapy. The risk of embolism, adjusted for known risk factors, was increased 3-fold in patients with device-detected AF episodes longer than $24 \mathrm{~h}$. The Mode Selection Trial studied 312 patients with permanent pacemakers and found that atrial tachyarrhythmias lasting more than 5 min were associated with a 2.8-fold increase in the risk of stroke [32]. A retrospective analysis of pacemaker patients by Botto et al. [33] found that patients at low risk $\left(\mathrm{CHADS}_{2}=0\right)$ had a low risk of stroke regardless of their AF burden. Likewise, patients at a high risk $\left(\mathrm{CHADS}_{2} \geq 3\right)$ have a high risk of stroke even with no documented AF. For the intermediate-risk group, however, the risk of stroke depended on the patient's AF burden as patients with more AF were found to have an increased risk of stroke. This study also compared traditional methods of monitoring patients for AF episodes with recordings from the implanted devices, noting that the occasional Holter monitoring typically done to assess AF burden had low sensitivity and poor negative predictive value [33]. In sum, these studies highlight the uncertainty surrounding the minimum AF duration needed to cause a stroke and raise important questions as to the appropriate threshold for anticoagulation therapy in patients in whom the duration of AF can be reliably measured.

\section{Antiplatelet Therapy as an Alternative to Warfarin}

Warfarin has been shown to be superior to aspirin monotherapy as well as combination antiplatelet therapy of aspirin plus clopidogrel in preventing stroke and systemic embolism in patients with AF [34]. Some patients with AF and concomitant stroke risk factors may be unsuitable for anticoagulation because of refusal to comply with regular INR monitoring, fall risk or prior major hemorrhage due to an irreversible cause. For these patients, the standard therapy is aspirin, though aspirin has not been found to be superior to placebo [35]. The Atrial Fibrillation Clopidogrel Trial with Irbesartan for Prevention of Vascular Events compared aspirin with combined aspirin and clopidogrel in patients with AF who were judged to be warfarin ineligible [36]. The combination therapy resulted in a $0.9 \%$ decrease in the absolute risk of stroke and an increase in the risk of major bleeding (2.0 vs. $1.3 \%)$. Though this result suggests that the bleeding risks of combination therapy outweigh its benefits in most patients, such therapy may be sufficient in patients who are already receiving it following a coronary intervention, are at a lower stroke risk or are warfarin ineligible.

\section{New Anticoagulants}

Warfarin's many disadvantages have prompted a search for oral anticoagulants that are more predictable in their anticoagulant effects, easier to administer and potentially safer. Other oral vitamin $\mathrm{K}$ antagonists are being explored, as well as two alternate classes of anticoagulants: the direct thrombin inhibitors (DTIs) and factor Xa inhibitors. DTIs and factor Xa inhibitors have minimal drug and food interactions, and they require no dosage adjustments or hematologic monitoring.

\section{Direct Thrombin Inhibitors}

The DTIs include ximelagatran and dabigatran, the first new anticoagulant to receive FDA approval. The earliest member of this class to be studied extensively was ximelagatran. Ximelagatran was proven noninferior to 
dose-adjusted warfarin, with a similar rate of major bleeding with the two treatments $[37,38]$. However, the hepatotoxicity of ximelagatran led to its withdrawal prior to FDA review. The value of ximelagatran, however, was proof of principle that a DTI could be at least as effective as warfarin in high-risk AF patients, without the logistic drawbacks of warfarin.

More recently, the RE-LY (Randomized Evaluation of Long-Term Anticoagulant Therapy, Warfarin, Compared with Dabigatran) trial compared the DTI dabigatran with dose-adjusted warfarin in 18,113 patients with nonvalvular AF [39]. The end point was stroke (ischemic and hemorrhagic) and systemic embolism. Two doses of dabigatran were compared with warfarin and though the dose of dabigatran was double-blinded, assignment to warfarin or dabigatran was not blinded.

Low-dose dabigatran (110 mg twice daily) was shown to be noninferior to warfarin for the primary end point of all stroke and systemic embolism (1.53\% per year for dabigatran vs. $1.69 \%$ per year for warfarin; $\mathrm{p}$ for noninferiority $<0.001)$. High-dose dabigatran $(150 \mathrm{mg}$ twice daily) was superior to warfarin for the primary end point (1.11 vs. $1.69 \%$ per year: $p$ for superiority $<0.001$ ). Most of the benefits of high-dose dabigatran over warfarin were for stroke prevention, with a $36 \%$ relative risk $(R R)$ reduction in favor of the former $(\mathrm{p}<0.001)$. Conversely, lowdose dabigatran demonstrated safety superior to that of warfarin, with significantly less major bleeding (2.71 vs. $3.36 \%$ per year; $p=0.03$ ). The risk of major bleeding (intracranial and extracranial hemorrhage) with high-dose dabigatran was nonsignificantly lower than that with warfarin ( 3.11 vs. $3.36 \%$ per year; $p=0.31)$. Although all anticoagulant-associated bleeding has the potential to be life-threatening, anticoagulation-associated hemorrhagic stroke carries a 76\% risk of death or permanent disability and is the most feared complication of this therapy [15]. Importantly, the risk of hemorrhagic stroke with both dosages of dabigatran was significantly lower than with warfarin (high-dose dabigatran vs. warfarin - RR reduction, 74\%; low-dose dabigatran vs. warfarin - RR reduction, 69\%), although the difference between the two doses was not statistically significant itself. There was a slightly higher, though statistically nonsignificant, risk of myocardial infarction in patients taking dabigatran than in those on warfarin $(\mathrm{RR}=1.29, \mathrm{p}=0.09$, and $\mathrm{RR}=1.27$, $\mathrm{p}=0.12$ for dabigatran, respectively), and there were more medication discontinuations with dabigatran than warfarin, which were largely the result of dyspepsia in patients receiving dabigatran [40].
A subsequent analysis of the RE-LY data regarding the bleeding risks associated with either dose of dabigatran demonstrated that rates of extracranial bleeding increased with age and were comparable to or slightly higher than the rates of extracranial bleeding with warfarin in patients over 75 years of age. Rates of intracranial bleeding, though, were significantly lower than with warfarin and were not affected by age (RR for $150 \mathrm{mg}$ dabigatran compared to warfarin: 0.43 in patients under the age of 75 and 0.42 in patients 75 or older) [41].

A cost-effectiveness analysis of dabigatran compared to warfarin by Shah and Gage [42] concluded that dabigatran was cost-effective for patients at a high risk for ischemic strokes (defined as $\mathrm{CHADS}_{2} \geq 3$ ). For patients at moderate risk of stroke $\left(\mathrm{CHADS}_{2} \geq 2\right)$, warfarin was more cost-effective provided that the time in the therapeutic range was greater than $57.1 \%$ [42]. This analysis determined that dabigatran was not cost-effective for patients with a $\mathrm{CHADS}_{2}$ score of 1 , though an analysis by Freeman et al. [43] concluded otherwise, primarily due to differences in their analyses. Both of these analyses were conducted based on cost data in the USA and therefore may not be applicable in other countries.

Based on the results of the RE-LY trial, dabigatran (Pradaxa, Boehringer-Ingelheim) was approved by the FDA in October 2010 for stroke prevention in patients with nonvalvular AF at a dose of $150 \mathrm{mg}$ twice a day in patients with creatinine clearance $>30 \mathrm{ml} / \mathrm{min}$ and $75 \mathrm{mg}$ twice a day in patients with creatinine clearance between 15 and $30 \mathrm{ml} / \mathrm{min}$. The $110-\mathrm{mg}$ dose tested in the RE-LY trial was not approved for use in the USA as it did not improve the risk-benefit profile of dabigatran in any subgroup. Even among patients with moderate renal impairment, defined as creatinine clearance between 30 and 50 $\mathrm{ml} / \mathrm{min}$, the $150-\mathrm{mg}$ dose of dabigatran was more effective than the 110-mg dose as it decreased the rate of strokes by almost half ( 1.3 vs. 2.4 events/100 patientyears) while not increasing the rate of major bleeding (5.3 vs. 5.7 events/100 patient-years) $[44,45]$. However, the 110 -mg dose is approved in most other countries, including all of Europe.

As a DTI, dabigatran has several lifestyle benefits as compared to warfarin in that it is not known to interact with any foods, has consistent dosing and does not require hematologic monitoring. It also has a much more rapid effect than warfarin, with an onset of action just $0.5-2 \mathrm{~h}$ and a half-life of $12-17 \mathrm{~h}$ [46]. Dabigatran has significant interactions with several antiarrhythmic drugs such as amiodarone and dronedarone. As the latter two inhibit the $p$-glycoprotein efflux transporter, concurrent 
use with dabigatran may lead to high serum levels of dabigatran and patients should be monitored, though no dose adjustments are recommended at this time. In Europe, however, patients taking verapamil are recommended to receive the $110-\mathrm{mg}$ dose of dabigatran. An advantage of warfarin over dabigatran is that there is currently no antidote to dabigatran, so in the case of severe hemorrhage or overdose, supportive therapy is the only option. Recently, however, an antibody has been under development that may in the future be an effective and rapid antidote for dabigatran [47].

\section{New Vitamin K Antagonists}

Tecarfarin is a novel oral vitamin K epoxide reductase antagonist [48]. It is a structural analog of warfarin, highly protein bound (99\%) and metabolized by carboxylesterases in the hepatic microsomes. It has a mechanism of action identical to that of warfarin, though it differs substantially in that it is not metabolized by the CYP450 system. In theory then, it offers the possibility of effective anticoagulation that can be monitored by INR, but with fewer CY 450 -mediated drug-drug and drug-food interactions. As such it is expected to surpass warfarin in the percentage of time in the therapeutic range. Trials have yet to compare it with warfarin.

\section{Factor Xa Inhibitors}

Two oral factor Xa inhibitors, rivaroxaban and apixaban, have recently been studied as alternatives to warfarin for stroke prevention in high-risk patients with $\mathrm{AF}$. Both agents offer potential advantages over warfarin similar to those of DTIs, namely consistent dosing without significant food or drug interactions or the need for monitoring. Rivaroxaban was compared with warfarin in patients with high-risk AF in ROCKET-AF (Rivaroxaban Once Daily Oral Direct Factor Xa Inhibition Compared with Vitamin K Antagonism for Prevention of Stroke and Embolism Trial in Atrial Fibrillation), a randomized, double-blind, double-dummy trial of 14,269 patients. The end point was any type of stroke or systemic embolism. A once daily dose of $20 \mathrm{mg}$ rivaroxaban was compared with warfarin titrated to an INR of 2.5. Notably, the mean $\mathrm{CHADS}_{2}$ score in this study was 3.5, much higher than for other studies in AF patients including RE-LY where the mean $\mathrm{CHADS}_{2}$ score was 2.1 [49]. The ROCKET-AF trial demonstrated that rivaroxaban was noninferior to warfarin for the prevention of stroke or systemic embolism, but unlike dabigatran, rivaroxaban did not decrease the risk of ischemic stroke. The overall risk of bleeding, both major and nonmajor clinically rel- evant bleeding, was comparable, but there was a decreased risk of intracranial and fatal bleeding in the rivaroxaban group [50].

Apixaban has been compared to aspirin in the study AVERROES (Apixaban versus Acetylsalicylic Acid to Prevent Stroke in Atrial Fibrillation Patients Who Have Failed or Are Unsuitable for Vitamin K Antagonist Treatment). This randomized double-blind study involved 5,599 patients with a mean $\mathrm{CHADS}_{2}$ score of 2.0 and compared a twice daily dose of $5 \mathrm{mg}$ apixaban with 81$324 \mathrm{mg}$ aspirin. This trial was terminated early due to the clear benefit of apixaban over aspirin in reduction of strokes $(0.45,95 \% \mathrm{CI}=0.32-0.62, \mathrm{p}<0.001)$ in this population [51]. Apixaban has recently been compared to warfarin in the ARISTOTLE trial (Apixaban for the Prevention of Stroke in Subjects with Atrial Fibrillation). This trial involved 18,201 patients with a mean $\mathrm{CHADS}_{2}$ of 2.1 and a median duration of 1.8 years of follow-up. Patients were randomized to a twice daily dose of apixaban $(5 \mathrm{mg})$ or warfarin titrated to an INR of 2.0-3.0. Apixaban was found to be superior to warfarin for the prevention of stroke and systemic embolism (hazard ratio $=0.79, \mathrm{p}=0.01$ ) while also demonstrating a decreased risk of bleeding (hazard ratio $=0.69, \mathrm{p}<0.001$ ). Importantly, the rate of intracranial hemorrhage was significantly lower for apixaban $(0.24$ vs. $0.47 \%$ per year for warfarin, $\mathrm{p}<0.001)$, and overall mortality was also reduced (hazard ratio $=0.89, \mathrm{p}=0.047$ ) [52].

Several other factor Xa inhibitors are currently in development. Edoxaban (DU-176b) is currently in a phase 3 trial (ENGAGE-AF-TIMI 48; Global Study to Assess the Safety and Effectiveness of DU-176b versus Standard Practice of Dosing with Warfarin in Patients with Atrial Fibrillation) estimated to be completed in March 2012 $[53,54]$. Betrixaban and YM150 have recently finished phase 2 trials [53].

\section{Occlusion Devices}

Autopsy studies suggest that more than $90 \%$ of cerebral emboli in patients with AF originate in the LAA [19]. For this reason, it is theoretically desirable to isolate the LAA from the circulation, presumably preventing embolism from this site, even after anticoagulation has been discontinued. Percutaneous devices deliverable via transseptal catheters have been developed for this purpose. For example, LAA closure with the Watchman device (Atritech, Plymouth, Minn., USA) was compared with warfarin in 707 high-risk AF patients; the patients were fol- 
lowed up for the primary end point of stroke, cardiovascular death, or systemic embolism. There were fewer primary end points in the device arm than in the warfarin arm of this study, but the results were statistically nonsignificant. This result was sufficient to establish the device's noninferiority to warfarin. However, there were significantly more safety end points with device implantation, including pericardial effusion requiring drainage, and device embolization [55]. A review of the results from the nonrandomized Continued Access Protocol registry for the Watchman device showed a lower rate of complications such as pericardial effusion, suggesting that greater operator experience decreased the rate of major complications [56]. Additionally, patients who received the Watchman device remained on warfarin anticoagulation for at least 45 days after implantation. After 45 days, $14 \%$ of the patients had to continue warfarin, and $8 \%$ had to continue warfarin beyond 6 months because of incomplete closure of the LAA [55]. In a 6-year follow-up of 75 patients who had received the Watchman device, $91 \%$ remained off warfarin. In a total of 368 patient-years of follow-up, there were 2 embolic strokes $(0.5 \%$ actual stroke rate), compared with the $5.75 \%$ rate that would be expected based on the mean $\mathrm{CHADS}_{2}$ score of 1.8 for these patients [57].

Because of the requirement for at least short-term warfarin therapy after implantation of the device, LAA occlusion has not yet been an option for patients with contraindications to anticoagulation. Recently, the Watchman device was implanted in 92 patients unable to take warfarin in the ASA and Plavix registry. After implantation, these patients received clopidogrel for 6 months and lifelong aspirin. At 6 months of follow-up, 2 patients had experienced ischemic strokes, though imaging studies did not detect a thrombus on the device. Follow-up is ongoing, but the initial results suggest that implantation of the Watchman device may be possible even in a subset of patients who are unable to take anticoagulants [58].

A second type of LAA occlusion device, the Amplatzer Cardiac Plug (AGA, Minneapolis, Minn., USA) has been implanted in patients with contraindications to warfarin in Asia and Europe. Postimplantation treatment was 1-3 months of clopidogrel and lifelong aspirin. Initial results from the 19 patients who received the device in the Asia study showed no residual leakage around the device and no cases of stroke or systemic embolism at a mean follow-up of 12.7 months [59]. Of the 132 patients who received the device in Europe, there was a 7\% rate of major complications including pericardial effusion and stroke. In view of the relatively high risk of stroke during device implantation, Park et al. [60] concluded that Amplatzer implantation in patients with a $\mathrm{CHADS}_{2}$ of 1 is not recommended as the rate of strokes during the procedure $(2.0 \%)$ approaches the rate of strokes for that group in general (2.8\%). For higher-risk patients, however, the Amplatzer device may prove beneficial, especially in those patients unable to take anticoagulation [60].

The role of LAA occlusion is unclear [61]. It may be a viable alternative to long-term anticoagulation in highrisk AF patients who can tolerate short-term anticoagulation but in whom long-term anticoagulation is unadvisable. Such patients might include those with cerebral amyloid angiopathy and high-risk AF or those with recent AF-associated ischemic stroke who have a very high risk of gastrointestinal hemorrhage. There is evidence that LAA occlusion devices may become neo-endothelialized over time, and anticoagulation may be safe to discontinue [62]. LAA closure may also be a viable treatment for patients with an absolute contraindication to any anticoagulation, but further research is necessary to confirm these hypotheses.

Surgical ligation and, in certain cases, amputation of the LAA has also been attempted. Given the invasiveness of the approach, it is limited to patients who are already undergoing open-heart surgery. One retrospective study of 205 patients with previous mitral valve replacement contained 58 patients who had undergone ligation of the left atrial appendage at the time of surgery [63]. In multivariate analysis, the only independent predictors of a future embolic event were absence of LAA ligation or presence of left atrial thrombus on echocardiography. The incidence of an embolic event among those with LAA ligation was significantly lower than among those without it (3 vs. 17\%). Because of these findings, the 2006 American College of Cardiology/American Heart Association guidelines on the management of valvular heart disease recommended amputation of the LAA at the time of mitral valve surgery [64]. A recent analysis of multiple trials involving LAA ligation, however, is less optimistic as ligation is often incomplete, resulting in a substantial risk of strokes [65]. In the future, more effective methods of ligating the LAA could result in a decreased stroke risk.

One method currently being studied involves a minimally invasive thorascopically guided endoloop snare and has been described in 15 patients with AF [66]. The authors note that the procedure was successful in 14 patients, while 1 had severe bleeding requiring open conversion. At a follow-up of 42 months, there were 2 strokes, a rate of $4 \%$ a year. Recently, percutaneous ligation of the LAA has 
been accomplished using the LARIAT snare (SentreHeart Inc., Palo Alto, Calif., USA). In a study of 82 patients who underwent the procedure, ligation of the LAA was successfully performed in 78 of them, and $73 / 78$ patients had acute closure of the LAA while the remaining 5 had a $<3$ $\mathrm{mm}$ jet identified by color flow Doppler sonography. At 1 month, 67/70 had complete closure and 3 patients had a $<2$-mm jet on Doppler sonography. At the 3 -month follow-up, 37/37 patients had complete closure of the LAA. There were no device-related complications in this study, but several patients were excluded from the procedure due to having a superiorly oriented LAA, a thrombus in the LAA, or LAA size greater than $40 \mathrm{~mm}$ [67]. An earlier study involving the LARIAT snare encountered complications when performing the procedure on patients with pectus excavatum [68]. Use of the LARIAT snare did not require the patients to take anticoagulants, and a study of $10 \mathrm{AF}$ patients intolerant to oral anticoagulants who underwent the procedure found no cases of postdevice thrombus in the early follow-up [69]. These results suggest that percutaneous closure of the LAA may in the future provide an alternative to oral anticoagulants for stroke prevention, but further studies are required.

\section{Intermittent Antithrombotic Therapy}

Alternate stroke prevention strategies are being developed that might spare patients with infrequent or shortlived paroxysms of AF the risks and inconveniences of continuous anticoagulation. These strategies are being examined in individuals with dual-chamber pacemakers, cardioverter-defibrillator and cardiac resynchronization therapy defibrillator devices. As current device technology allows for nearly real-time continuous remote monitoring, it is conceivable that patients with infrequent AF episodes may start and stop anticoagulation only around the time of an AF episode. This theory is currently being examined in the Impact of Biotronic Home Monitoring Guided Anticoagulation on Stroke Risk in Patients with Implanted Cardioverter-Defibrillator and Cardiac Resynchronization Therapy Defibrillator Devices study and the Tailored Anticoagulation for Noncontinuous AF trial [70].

\section{Sinus Rhythm to Prevent Stroke}

A final strategy to prevent strokes in AF patients is to maintain them in sinus rhythm ('rhythm control'). Although it seems logical that maintaining normal sinus rhythm would result in a reduced risk of stroke, there are few data at this time to support this assumption. The issue is complicated by the fact that much AF is asymptomatic, symptoms are unreliable measures of rhythm control in those patients who do have them, antiarrhythmic drugs are often unsuccessful at maintaining sinus rhythm, and symptomatic episodes of AF can be converted into asymptomatic episodes by drug or ablation therapy [71]. Furthermore, external monitoring has limited sensitivity for detecting $\mathrm{AF}$ and long-term external monitoring of patients is impractical. These points underscore the unreliable nature of self-reported or periodic monitoring for recurrences of AF, making it difficult to determine whether a rhythm control strategy is effectively preventing AF. This caveat supports the current practice of continuing anticoagulation in most $\mathrm{AF}$ patients treated with a rhythm control strategy using antiarrhythmic agents. There is growing interest in the possibility that newer approaches to AF treatment may provide sufficient rhythm control to allow anticoagulation to be discontinued. If so, such treatments might be attractive alternatives for AF patients who are at risk for thromboemboli but are poor anticoagulation candidates. Pulmonary vein isolation procedures are being used increasingly for treating AF and may provide superior rhythm control compared with antiarrhythmic therapy [72]. Uncontrolled data suggest AF ablation may be associated with a decreased risk of stroke and may allow for the safe cessation of anticoagulation therapy in some patients $[73,74]$. Newer antiarrhythmic agents have also been associated with a reduced risk of stroke [75]. In the A Trial with Dronedarone to Prevent Hospitalization or Death in Patients with Atrial Fibrillation study, dronedarone was found to reduce the risk of stroke in AF patients. Potential mechanisms for this reduction include decreasing blood pressure and lowering heart rate. Although it is possible that the reduction in strokes was due to the patients having better rhythm control, even patients who were often found to be in AF exhibited this decrease in stroke rate [75]. The efficacy of dronedarone for preventing cardiovascular events was being studied in the Permanent Atrial Fibrillation Outcome Study Using Dronedarone on Top of Standard Therapy, but this trial was terminated early due to an increase in cardiovascular events in this population [76]. These findings suggest that rhythm control with medication may not alone reduce the risk of stroke, but more definitive treatments such as ablation may allow for safe discontinuation of anticoagulants. 


\section{Conclusions}

With the recent approval of dabigatran and rivaroxaban, patients with high-risk AF who can tolerate anticoagulation now have three options for stroke prevention. Warfarin, dabigatran and rivaroxaban each have individual risks and lifestyle benefits that must be considered with each patient.

However, for those unable or unwilling to use anticoagulants indefinitely, recent clinical trial data suggest that in some patients, the risk-benefit ratio may favor the combination of aspirin and clopidogrel, or percutaneous occlusion of the LAA, for better stroke prevention than aspirin monotherapy. The advent of less cumbersome, more predictable and safer oral anticoagulants may decrease the proportion of high-risk AF patients unable to comply with anticoagulation therapy. Finally, new cardiac monitoring technology offers clinicians the ability to detect AF and offer selective anticoagulation. These advances improve the outlook for preventing both first and recurrent stroke in patients at risk for AF-related stroke.

\section{Disclosure Statement}

Dr. R.S. Passman serves as a speaker for Boehringer-Ingelheim, Sanofi-Aventis and Medtronic, is a consultant to Medtronic, and receives compensation for work on the steering committee of the CRYSTAL-AF study.

\section{References}

1 Go AS, Hylek EM, Phillips KA, Chang Y, Henault LE, Selby JV, Singer DE: Prevalence of diagnosed atrial fibrillation in adults: national implications for rhythm management and stroke prevention: the Anticoagulation and Risk Factors in Atrial Fibrillation (ATRIA) study. JAMA 2001;285:2370-2375.

-2 Marini C, De Santis F, Sacco S, Russo T, Olivieri L, Totaro R, Carolei A: Contribution of atrial fibrillation to incidence and outcome of ischemic stroke: results from a population-based study. Stroke 2005;36:1115-1119.

$\checkmark 3$ Wolf PA, Abbott RD, Kannel WB: Atrial fibrillation as an independent risk factor for stroke: the Framingham Study. Stroke 1991; 22:983-988.

4 Roger VL, Go AS, Lloyd-Jones DM, Adams RJ, Berry JD, Brown TM, Carnethon MR, Dai S, de Simone G, Ford ES, Fox CS, Fullerton HJ, Gillespie C, Greenlund, KJ, Hailpern SM, Heit JA, Ho PM, Howard VJ, Kissela BM, Kittner SJ, Lackland DT, Lichtman JH, Lisabeth LD, Makuc DM, Marcus GM, Marelli A, Matchar DB, McDermott MM, Meigs JB, Moy CS, Mozaffarian D, Mussolino ME, Nichol G, Paynter NP, Rosamond WD, Sorlie PD, Stafford RS, Turan TN, Turner MB, Wong ND, Wylie-Rosett J: Heart Disease and Stroke Statistics - 2011 Update, A Report from the American Heart Association. Circulation 2011;123:e19-e209.

$\checkmark 5$ Hannon N, Sheehan O, Kelly L, Marnane M, Merwick A, Moore A, Kyne L, Duggan J, Moroney J, McCormack PM, Daly L, Fitz-Simon N, Harris D, Horgan G, Williams EB, Furie KL, Kelly PJ: Stroke associated with atrial fibrillation - incidence and early outcomes in the North Dublin Population Stroke Study. Cerebrovasc Dis 2010;29:43-49.

6 Tu HT, Campbell BC, Christensen S, Collins M, De Silva DA, Butcher KS, Parsons MW, Desmond PM, Barber PA, Levi CR, Bladin CF, Donnan GA, Davis SM: Pathophysiological determinants of worse stroke outcome in atrial fibrillation. Cerebrovasc Dis 2010;30:389-395.

7 Risk factors for stroke and efficacy of antithrombotic therapy in atrial fibrillation: analysis of pooled data from five randomized controlled trials. Arch Intern Med 1994; 154:1449-1457.

$\checkmark 8$ Sacco RL, Adams R, Albers G, Alberts MJ, Benavente O, Furie K, Goldstein LB, Gorelick P, Halperin J, Harbaugh R, Johnston SC, Katzan I, Kelly-Hayes M, Kenton EJ, Marks M, Schwamm LH, Tomsick T: Guidelines for prevention of stroke in patients with ischemic stroke or transient ischemic attack: a statement for healthcare professionals from the American Heart Association/American Stroke Association Council on Stroke: cosponsored by the Council on Cardiovascular Radiology and Intervention: the American Academy of Neurology affirms the value of this guideline. Stroke 2006;37:577-617.

$\checkmark 9$ Mant J, Hobbs FD, Fletcher K, Roalfe A, Fitzmaurice D, Lip GY, Murray E, BAFTA Investigators: Warfarin versus aspirin for stroke prevention in an elderly community population with atrial fibrillation (the Birmingham Atrial Fibrillation Treatment of the Aged Study, BAFTA): a randomised controlled trial. Lancet 2007;370:493-503.

10 Gage BF, Eby C, Milligan PE, Banet GA, Duncan JR, McLeod HL: Use of pharmacogenetics and clinical factors to predict the maintenance dose of warfarin. Thromb Haemost 2004;91:87-94.

11 Bungard TJ, Ghali WA, Teo KK, McAlister FA, Tsuyuki RT: Why do patients with atrial fibrillation not receive warfarin? Arch Intern Med 2000;160:41-46.

$>12$ Hylek EM, Skates SJ, Sheehan MA, Singer DE: An analysis of the lowest effective intensity prophylactic anticoagulation for patients with nonrheumatic atrial fibrillation. N Engl J Med 1996;335:540-546.
13 Baker WL, Cios DA, Sander SD, Coleman CI: Meta-analysis to assess the quality of warfarin control in atrial fibrillation patients in the United States. J Manag Care Pharm 2009; 15:244-252.

14 Connolly SJ, Pogue J, Eikelboom J, Flaker G, Commerford P, Franzosi MG, Healey JS, Yusuf S, ACTIVE-W Investigators: Benefit of oral anticoagulant over antiplatelet therapy in atrial fibrillation depends on the quality of international normalized ratio control achieved by centers and countries as measured by time in therapeutic range. Circulation 2008; 118:2029-2037.

15 Fang MC, Go AS, Chang Y, Hylek EM, Henault LE, Jensvold NG, Singer DE: Death and disability from warfarin-associated intracranial and extracranial hemorrhages. Am J Med 2007;120:700-705.

-16 Fang MC, Chang Y, Hylek EM, Rosand J, Greenberg SM, Go AS, Singer DE: Advanced age, anticoagulation intensity, and risk for intracranial hemorrhage among patients taking warfarin for atrial fibrillation. Ann Intern Med 2004;141:745-752.

$\checkmark 17$ Buckingham TA, Hatala R: Anticoagulants for atrial fibrillation: why is the treatment rate so low? Clin Cardiol 2002;25:447-454.

18 Go AS, Hylek EM, Chang Y, Phillips KA, Henault LE, Capra AM, Jensvold NG, Selby JV, Singer DE: Anticoagulation therapy for stroke prevention in atrial fibrillation: how well do randomized trials translate into clinical practice? JAMA 2003;290:2685-2692.

19 Stoddard MF, Dawkins PR, Prince CR, Ammash NM: Left atrial appendage thrombus is not uncommon in patients with acute atrial fibrillation and a recent embolic event: a transesophageal echocardiographic study. J Am Coll Cardiol 1995;25:452-459.

20 Guazzi M, Arena R: Endothelial dysfunction and pathophysiological correlates in atrial fibrillation. Heart 2009;95:102-106. 
-21 Minamino T, Kitakaze M, Sanada S, Asanuama H, Kurotobi T, Koretsune Y, Fukunami M, Kuzuya T, Hoki N, Hori M: Increased expression of $\mathrm{P}$-selectin on platelets is a risk factor for silent cerebral infarction in patients with atrial fibrillation: role of nitric oxide. Circulation 1998;98:1721-1727.

-22 Takahashi N, Ishibashi Y, Shimade T, Sakane T, Ohata S, Sugamori T, Ohta Y, Inoue S, Nakamura K, Shimizu H, Katoh H, Sano K, Murakami Y, Hashimoto M: Atrial fibrillation impairs endothelial function of forearm vessels in humans. I Cardiac Fail 2001;7:45-54.

-23 Guazzi M, Berti M, Belletti S, Reina G, Guazzi MD: Exercise metaboreflex activation and endothelial function impairment in atrial fibrillation. Am J Physiol Heart Circ Physiol 2006;291:H2396-H2402.

-24 Guazzi M, Belletti S, Lenatti L, Bianco E, Guazzi MD: Effects of cardioversion of atrial fibrillation on endothelial function in hypertension and diabetes. Eur J Clin Invest 2007;37:26-34.

25 Schultz CD, Willoughby SR, Lim HS, Alasady M, Lau DH, Mahajay R, Najyar S, Roberts-Thomson KC, Young GD, Sanders P: Left atrial endothelial dysfunction and inflammation in atrial fibrillation (abstract). HRS 2011, Heart Rhythm Society 32nd Annual Scientific Sessions, San Francisco, 2011.

-26 Roldan V, Marin F, Muina B, Torregrosa JM, Hernandez-Romero D, Valdes M, Vicente V, Lip GYH: Plasma von Willebrand factor levels are an independent risk factor for adverse events including mortality and major bleeding in anticoagulated atrial fibrillation patients. J Am Coll Cardiol 2011;57:2496-2504.

-27 Lane DA, Lip G: Female gender is a risk factor for stroke and thromboembolism in atrial fibrillation patients. Thromb Haemost 2009; 101:802-805.

-28 Frost L, Engholm G, Johnsen S, Moller H, Husted S: Incident stroke after discharge from the hospital with a diagnosis of atrial fibrillation. Am J Med 2000;108:36-40.

-29 Van Staa TP, Setakis E, Di Tanna GL, Lane DA, Lip GY: A comparison of risk stratification schemes for stroke in 79,884 atrial fibrillation patients in general practice. J Thromb Haemost 2011;9:39-48.

30 The Stroke Prevention in Atrial Fibrillation Investigators Committee on Echocardiography: Transesophageal echocardiographic correlates of thromboembolism in high-risk patients with nonvalvular atrial fibrillation. Ann Intern Med 1998;128:639-647.

-31 Capucci A, Santini M, Padeletti L, Gulizia M, Botto G, Boriani G, Ricci R, Favale S, Zolezzi F, Di Belardino N, Molon G, Drago F, Villani GQ, Mazzini E, Vimercati M, Grammatico A: Monitored atrial fibrillation duration predicts arterial embolic events in patients suffering from bradycardia and atrial fibrillation implanted with antitachycardia pacemakers. J Am Coll Cardiol 2005;46:1913-1920.
32 Glotzer TV, Hellkamp AS, Zimmerman J, Sweeney MO, Yee R, Marinchak R, Cook J, Paraschos A, Love J, Radoslovich G, Lee KL, Lamas GA, MOST Investigators: Atrial high rate episodes detected by pacemaker diagnostics predict death and stroke: report of the Atrial Diagnostics Ancillary Study of the Mode Selection Trial (MOST). Circulation 2003;107:1614-1619.

33 Botto GL, Padeletti L, Santini M, Capucci A, Gulizia M, Zolezzi F, Favale S, Molon G, Ricci R, Biffi M, Russo G, Vimercati M, Corbucci G, Boriani G: Presence and duration of atrial fibrillation detected by continuous monitoring: crucial implications for the risk of thromboembolic events. J Cardiovasc Electrophysiol 2009;20:241-248.

34 Connolly S, Pogue J, Hart R, Pfeffer R, Hohnloser S, Chrolavicius S, Pfeffer R, Hohnloser S, Yusuf S: Clopidogrel plus aspirin versus oral anticoagulation for atrial fibrillation in the Atrial Fibrillation Clopidogrel Trial with Irbesartan for Prevention of Vascular Events (ACTIVE W): a randomised controlled trial. Lancet 2006;367:1903-1912.

-35 Koudstaal PJ, European Atrial Fibrillation Trial Study Group: Secondary prevention in non-rheumatic atrial fibrillation after transient ischaemic attack or minor stroke. Lancet 1993;342:1255-1262.

36 Connolly SJ, Pogue J, Hart RG, Hohnloser S, Pfeffer R, Chrolavicius S, Yusuf S: Effect of clopidogrel added to aspirin in patients with atrial fibrillation. N Engl J Med 2009;360: 2066-2078.

-37 Albers GW, Diener HC, Frison L, Grind M, Nevinson M, Partridge S, Halperin JL, Horrow J, Olsson SB, Peterson P, Vahanian A, SPORTIF V Investigators: Ximelagatran vs warfarin for stroke prevention in patients with nonvalvular atrial fibrillation: a randomized trial. JAMA 2005;293:690-698

38 Olsson SB: Stroke prevention with the oral direct thrombin inhibitor ximelagatran compared with warfarin in patients with non-valvular atrial fibrillation (SPORTIF III): randomised controlled trial. Lancet 2003;362:1691-1698.

39 Connolly SJ, Ezekowitz MD, Yusuf S, Eikelboom J, Oldgren J, Parekh A, Pogue J, Reilly PA, Themeles E, Varrone J, Wang S, Alings M, Xavier D, Zhu J, Diaz R, Lewis BS, Darius H, Diener HC, Joyner CD, Wallentin L, RELY Investigators: Dabigatran versus warfarin in patients with atrial fibrillation. $\mathrm{N}$ Engl J Med 2009;361:1139-1151.

40 Connolly SJ, Ezekowitz MD, Yusuf S, Reilly PA, Wallentin L: Newly identified events in the RE-LY trial. N Engl J Med 2010;363: 1875-1876.
41 Eikelboom JW, Wallentin L, Connolly SJ, Ezekowitz M, Healey JS, Oldgren J, Yang S, Alings M, Kaatz S, Hohnloser SH, Diener HC, Franzosi MG, Huber K, Reilly P, Varrone J, Yusuf S: Risk of bleeding with 2 doses of dabigatran compared with warfarin in older and younger patients with atrial fibrillation: an analysis of the Randomized Evaluation of Long-Term Anticoagulant Therapy (RE-LY) trial. Circulation 2011;123:23632372.

42 Shah SV, Gage BF: Cost-effectiveness of dabigatran for stroke prophylaxis in atrial fibrillation. Circulation 2011;123:2562-2570.

43 Freeman JV, Zhu RP, Owens DK, Garber AM, Hutton DW, Go AS, Wang PJ, Turakhia MP: Cost-effectiveness of dabigatran compared with warfarin for stroke prevention in atrial fibrillation. Ann Intern Med 2011;154: $1-11$.

44 Wann LS, Curtis AB, Ellenbogen KA, Estes NA, Ezekowitz MD, Jackman WM, January CT, Lowe JE, Page RL, Slotwiner DJ, Stevenson WG, Tracy CM: 2011 ACCF/AHA/HRS focused update on the management of patients with atrial fibrillation (update on dabigatran). J Am Coll Cardiol 2011;57:13301337.

45 Beasley BN, Unger EF, Temple R: Anticoagulant options - why the FDA approved a higher but not a lower dose of dabigatran. N Engl J Med 2011;364:1788-1790.

46 Ezekowitz MD, Connolly S, Parekh A, Reilly PA, Varrone J, Wang S, Oldgren J, Themeles E, Wallentin L, Yusuf S: Rationale and design of RE-LY: randomized evaluation of longterm anticoagulant therapy, warfarin, compared with dabigatran. Am Heart J 2009;157: 808-810.

47 Van Ryn J, Litzenburger T, Waterman A, Canada K, Hauel N, Sarko C, Kroe-Barrett R, Singh S, Park J: Dabigatran anticoagulant activity is neutralized by an antibody selective to dabigatran in in vitro and in vivo models (abstract). ACC 2011, American College of Cardiology 60th Annual Scientific Sessions and Expo, New Orleans, 2011.

48 Ellis D, Usman MH, Milner P, Canafax D, Ezekowitz MD: The first evaluation of a novel vitamin $\mathrm{K}$ antagonist, tecarfarin (ATI5923), in patients with atrial fibrillation. Circulation 2009;120:1029-1035.

49 Executive Steering Committee on behalf of the ROCKET-AF Investigators: Rivaroxaban - once daily, oral, direct factor Xa inhibition compared with vitamin $\mathrm{K}$ antagonism for prevention of stroke and embolism trial in atrial fibrillation: rationale and design of the ROCKET-AF study. Am Heart J 2010; 159:340-347.

-50 Patel MR, Mahaffey KW, Garg J, Pan G, Singer DE, Hacke W, Breithardt G, Halperin JL, Hankey GJ, Piccini JP, Becker RC, Nessel CC, Paolini JF, Berkowitze SD, Fox KA, Califf RM: Rivaroxaban versus warfarin in nonvalvular atrial fibrillation. N Engl J Med 2011;365:883-891. 
-51 Connolly S, Eikelboom J, Joyner C, Diener HC, Hart R, Golitsyn S, Flaker G, Avezum A, Hohnloser SH, Diaz R, Talajic M, Zhu J, Pais P, Budaj A, Parkhomenko A, Jansky P, Commerford P, Tan RS, Sim KH, Lewis BS, van Miegham W, Lip GY, Kim JH, Lanas-Zanetti F, Gonzalez-Hermosillo A, Dans AL, Munawar M, O’Donnell M, Lawrence J, Lewis G, Afzal R, Yusuf S, AVERROES Investigators: Apixaban in patients with atrial fibrillation. N Engl J Med 2011;364:806-817.

- 52 Granger CB, Alexander JH, McMurray JJ, Lopes RD, Hylek EM, Hanna M, Al-Khalidi HR, Ansell J, Atar D, Avezum A, Bahit MC, Diaz R, Easton JD, Ezekowitz JA, Flaker G, Gargia D, Geraldes M, Gersh BJ, Golitsyn S, Goto S, Hermosillo AG, Hohnloser SH, Horowitz J, Mohan P, Jansky P, Lewis BS, Lopez-Sendon JL, Pais P, Parkhomenko A, Verheugt FW, Zhu J, Wallentin L: Apixaban versus warfarin in patients with atrial fibrillation. N Engl J Med 2011;365:981-992.

53 ClinicalTrials.gov. Washington DC. US National Institutes of Health. http://clinicaltrials.gov (accessed July 5, 2011).

-54 Ruff CT, Giugliano RP, Antman EM, Crugnale SE, Bocanegra T, Mercuri M, Hanyok J, Patel I, Shi M, Salazar D, McCabe CH, Braunwald E: Evaluation of the novel factor $\mathrm{Xa}$ inhibitor edoxaban compared with warfarin in patients with atrial fibrillation: design and rationale for the effective anticoagulation with factor Xa next generation in atrial fibrillation-thrombolysis in myocardial infarction study 48 (ENGAGE AF-TIMI 48). Am Heart J 2010;160:635-641.

55 Holmes DR, Reddy VY, Turi ZG, Doshi SK, Sievert H, Buchbinder M, Mullin CM, Sick P, PROTECT AF Investigators: Percutaneous closure of the left atrial appendage versus warfarin therapy for prevention of stroke in patients with atrial fibrillation: a randomised non-inferiority trial. Lancet 2009;374:534542.

56 Reddy VY, Holmes D, Doshi SK, Neuzil P, Kar S: Safety of percutaneous left atrial appendage closure: results from the Watchman left atrial appendage system for embolic protection in patients with AF (PROTECT AF) clinical trial and the continued access registry. Circulation 2011;123:417-424.

57 Sick PB, Turi ZG, Grube E, Schuler G, Hauptmann KE, Mishkel G, Yakubov S, Almany S, Holmes D: Stroke prevention in non-valvular atrial fibrillation: long-term results after 6 years of the Watchman left atrial appendage occlusion pilot study (poster). Innovation in Intervention, i2 Summit 2011 of the American College of Cardiology, New Orleans, 2011LA.

58 Reddy VY, Neuzil P, Schuler G, MobiusWinkler S, Sick P, Sievert H: LAA closure using the Watchman device in patients with contraindications to warfarin: preliminary results from the 'ASA Plavix Registry' (ASAP) (abstract). 32nd Annual Scientific Sessions of the Heart Rhythm Society, San Francisco, 2011.
59 Lam YY, Yip GW, Yu CM, Chan WW, Cheng BC, Yan BP, Clugston R, Yong G, Gattorna T, Paul V: Left atrial appendage closure with Amplatzer cardiac plug for stroke prevention in atrial fibrillation: initial Asia-Pacific experience. Catheter Cardiovasc Interv 2011, E-pub ahead of print.

60 Park JW, Bethencourt A, Sievert H, Santoro G, Meier B, Walsh K, Lopez-Minquez JR, Meerkin D, Valdes M, Ormerod O, Leithauser B: Left atrial appendage closure with Amplatzer cardiac plug in atrial fibrillation: initial European experience. Catheter Cardiovasc Interv 2011;77:700-706.

61 Maisel WH: Left atrial appendage occlusion - closure or just the beginning? N Engl J Med 2009;360:2601-2603.

62 Omran H, Schmidt H, Hardung D, Hammerstingl C, von der Recke G, Haas S, Buttner R, Luderitz B: Post mortem analysis of a left atrial appendage occlusion device (PLAATO) in a patient with permanent atrial fibrillation. J Interv Card Electrophysiol 2005; 14:17-20.

63 Garcia-Fernandez MA, Perez-David E, Quiles J, Peralta J, Garcia-Rojas I, Bermejo J, Moreno M, Silva J: Role of left atrial appendage obliteration in stroke reduction in patients with mitral valve prosthesis: a transesophageal echocardiographic study. J Am Coll Cardiol 2003;42:1253.

64 Bonow RO, Carabello BA, Chatterjee K, de Leon AC Jr, Faxon DP, Freed MD, Gaasch WH, Lytle BW, Nishimura RA, O'Gara PT, O'Rourke RA, Otto CM, Shah PM, Shanewise JS: 2008 focused update incorporated into the ACC/AHA 2006 guidelines for the management of patients with valvular heart disease: a report of the American College of Cardiology/American Heart Association Task Force on Practice Guidelines (Writing Committee to Revise the 1998 Guidelines for the Management of Patients with Valvular Heart Disease): endorsed by the Society of Cardiovascular Anesthesiologists, Society for Cardiovascular Angiography and Interventions, and Society of Thoracic Surgeons. Circulation 2008;118:e523.

65 Dawson AG, Asopa S, Dunning J: Should patients undergoing cardiac surgery with atrial fibrillation have left atrial appendage exclusion? Interact Cardiovasc Thorac Surg 2010; 10:306-311.

66 Blackshear JL, Johnson WD, Odell JA, Baker JS, Howard M, Pearce L, Stone C, Packer DL, Schaff HV: Thoracoscopic extracardiac obliteration of the left atrial appendage for stroke risk reduction in atrial fibrillation. J Am Coll Cardiol 2003;42:1249.

67 Lee RJ, Bartus K, Bednarek J, Lelakowski J, Myc J, Kapelak B, Sadowski J, Yakubov S: Long-term efficacy of a percutaneous approach for LAA ligation in patients with atrial fibrillation (poster). 32nd Annual Scientific Sessions of the Heart Rhythm Society, San Francisco, 2011.
68 Bartus K, Bednarek J, Myc J, Kapelak B, Sadowski J, Lelakowski J, Yakubov SJ, Lee RJ: Feasibility of closed-chest ligation of the left atrial appendage in humans. Heart Rhythm 2011;8:188-193.

69 Coffey JO, Doshi SK, Koruth JS, Miller MA, Viles-Gonzalez J, Skipitaris NT, Fischer A, d'Avila A, Dukkipati S, Reddy VY: Pericardial suture ligation of the left atrial appendage in patients intolerant to oral anticoagulation (poster). 32nd Annual Scientific Sessions of the Heart Rhythm Society, San Francisco, 2011.

-70 Ip J, Waldo AL, Li GY, Rothwell PM, Martin DT, Bersohn MM, Choucair WK, Akar JG, Wathen MS, Rohani P, Halperin JL, IMPACT Investigators: Multicenter randomized study of anticoagulation guided by remote rhythm monitoring in patients with implantable cardioverter-defibrillator and CRT-D devices: rationale, design, and clinical characteristics of the initially enrolled cohort: the IMPACT study. Am Heart J 2009; 158:364-370.

71 Page RL, Tilsch TW, Connolly SJ, Schnell DJ, Marcello SR, Wilkinson WE, Pritchett EL: Asymptomatic or 'silent' atrial fibrillation: frequency in untreated patients and patients receiving azimilide. Circulation 2003;107: 1141-1145.

72 Terasawa T, Balk EM, Chung M, Garlitski AC, Alsheikh-Ali AA, Lau J, Ip S: Systematic review: comparative effectiveness of radiofrequency catheter ablation for atrial fibrillation. Ann Intern Med 2009;151:191-202.

73 Pappone C, Rosanio S, Augello G, Gallus G, Vicedomini G, Mazzone P, Gulletta S, Gugliotta F, Pappone A, Santinelli V, Tortoriello V, Sala S, Zangrillo A, Crescenzi G, Benussi S, Alfieri O: Mortality, morbidity, and quality of life after circumferential pulmonary vein ablation for atrial fibrillation: outcomes from a controlled nonrandomized long-term study. J Am Coll Cardiol 2003;42: 185-197.

74 Oral H, Chugh A, Ozaydin M, Good E, Fortino J, Sankaran S, Reich S, Igic P, Elmouchi D, Tschopp D, Wimmer A, Dey S, Crawford T, Pelosi F Jr, Jongnarangsin K, Bogun F, Morady F: Risk of thromboembolic events after percutaneous left atrial radiofrequency ablation of atrial fibrillation. Circulation 2006;114:759-765.

75 Connolly SJ, Crijns HJ, Torp-Pedersen C, van Eickels M, Gaudin C, Page RL, Hohnloser SH, ATHENA Investigators: Analysis of stroke in ATHENA: a placebo-controlled, double-blind, parallel-arm trial to assess the efficacy of dronedarone $400 \mathrm{mg}$ BID for the prevention of cardiovascular hospitalization or death from any cause in patients with atrial fibrillation/atrial flutter. Circulation 2009;120:1174-1180.

76 Wood S: Dronedarone trial suspended due to $\mathrm{CV}$ events in permanent atrial fibrillation. http://www.theheart.org/article/1251405.do (accessed July 7, 2011). 